DOI: $10.4274 /$ tpa. 821

\title{
Mortality and morbidity in late-preterm newborns
}

\author{
PInar Binarbaş, Yasemin Akın, Fatma Narter, Berrin Telatar, Esra Polatoğlu, Turgut Ağzıkuru \\ Dr. Lütfi Kırdar Kartal Education and Research Hospital 1st Pediatrics Clinic, Istanbul, Turkey
}

\section{Summary}

Aim: There has been a gradual rise in late preterm infant rates in recent years. Although the late preterm infants have a lower risk compared to smaller preterms, some recent studies have suggested an incresed risk of mortality and morbidiy in this group compared to term infants. The aim of this study was to determine the rate of late-preterm births in our hospital, detect the neonatal mortality and morbidity of late-preterm newborns and compare the results with term newborns.

Material and Method: For this prospective study, the gestational age of all infants born alive in our hospital between May 1, 2009- May 1, 2010 were assessed using the mother's last menstrual period and the new Ballard test. Our study group consisted of 220 infants selected among infants born late-preterm (34 0/7 -36 6/7 weeks), while 200 term newborns constituted our control group. Newborns with major congenital abnormalities and whose families did not consent were excluded. The subjects were seen and evaluated at 72 hours and weekly for one month.

Results: During the study period 412 of $2582(15.2 \%)$ babies born in our hospital were late-preterms. The number and rate of neonatal ICU admissions of term and late preterm infants were $28(14 \%)$ and $172(54.5 \%)$, respectively. Respiratory problems in late-preterms were significantly more frequent (31.8\% versus $2 \%$ ). Mechanical ventilation was used in $20.9 \%$ of late-preterms, while no term newborns needed it. Late-preterms overall were more likely to have feeding problems ( $19.1 \%$ vs $0.5 \%)$, hyperbilirubinemia $(44.1 \%$ vs $7.5 \%)$, hypoglicemia $(6.4 \%$ vs $1.0 \%)$, hypotermia ( $14.5 \%$ vs $0 \%)$, and infection ( $15.9 \%$ vs $0 \%$ ). The mortality rate in late-preterm infants were 1 times more than term infants $(5.5 \%$ vs $0.5 \%)$.

Conclusions: Late-preterms have a significantly higher risk of morbidity and mortality compared to term newborns. They should be monitored closely interms of a higher risk of morbidity and a higher risk of admittion to hospital. (Turk Arch Ped 2013; 48: 17-22)

Key words: Preterm birth, late-preterm, neonatal morbidity, neonatal mortality

\section{Introduction}

Preterm birth rates (<37 gestational week) are increasing in many countries worldwide and is a universal health problem. This increase has been reported to be related with the increase in latepreterm births (34 0/7-36 6/7 gestational week) which constitute approximately $75 \%$ of preterm births $(1,2)$. Although the neonatal morbidity and mortality risks in late-preterm infants are much lower compared to preterm infants born before the 34th gestational week, there are limited number of short-term and longterm morbidity studies related with late-preterm newborns (3).

Most of the late-preterm infants are born with a normal birth weight, are frequently accepted as term infants $(4,5)$ and are generally followed up beside the mother postnatally. However, this group of newborns carry a higher risk in terms of morbidity and mortality compared to term infants $(6,7)$. Determining the morbidity rates and risk factors in these infants is important in terms of preventive studies and prospective planning.
In this study, we aimed to find the rate of late preterm newborns among live births during a period of one year in our hospital and the early neonatal morbidity and mortality rates in these infants.

\section{Material and Method}

This study which was designed to be a prospective study was conducted in infants who were born in Dr. Lütfi Kırdar Kartal Education and Research Hospital Gynecology and Obstetrics Clinic between May the 1st 2009 and May the 1st 2010 after obtaining ethics committee approval (number:77, 05.04.2009).

The New Ballard score was assessed by the study team in all infants born during the study. If the mother was sure, the last menstrual period date was used to determine the gestational age. In cases where the last menstrual period date was not reliable, the new Ballard score was used. The study group was composed of late-preterm newborns with a gestational age 
between 34 weeks and 0/7 days and 36 weeks and 6/7 days and the control group was composed of term newborns with a gestational age between 38 and 42 weeks whose families gave consent. Newborns with major congenital anomaly or chromosomal anomaly were excluded from the study. Infants included in the study were followed up regularly. Infants who did not return for follow-up visits were excluded from the study.

Each infant included in the study was recorded as soon as he/she was born. After the delivery he/she was examined by the study team, his/her antropometric body measures were determined and recorded. The infants were evaluated 48-72 hours after discharge from the hospital and examined at followup visits performed every week until one month of age.

Previously prepared forms were completed for each child included in the study and control groups. In these forms properties related with birth (birth place, mode of delivery, birth weight, birth height and head circumference, gestational week, maternal age, gender) and maternal risk factors which might have led to preterm delivery were interrogated. For the infants who were hospitalized in the neonatal intensive care unit (NICU) expanded forms including the data related with presence and cause of respiratory problem (transient tachypnea of the newborn, respiratory distress syndrome, neonatal pneumonia, lung hemorrhage, pneumothorax, apnea), MV time if mechanical ventilation (MV) was required, MV modes, hospitalization time in $\mathrm{NICU}$, diagnoses made, complications and mortality rates were constituted. Nasal continious positive airway pressure (nCPAP) was used in infants requiring mechanical ventilation and synchronized intermittent mandatory ventilation+ pressure support (SIMV+PS) modes were used in infants requiring intubation. A diagnosis of transient tachypnea of the newborn was made in presence of tachypnea which lasted at least for 12 hours $(>60 / \mathrm{min})$, mildly increased aeration, vascular congestion, perihilar interstitial prominence, mild cardiac enlargement on lung graphy and absence of other conditions which could lead to similar clinical findings (8). A diagnosis of respiratory distress syndrome was made by presence of clinical findings including tachypnea, nasal flaring, subcostal and intercostal retractions, cyanosis, groaning occuring in a few hours after delivery and marked radiological findings (diffuse reticular appearance, ground-glass appearance, air bronchogram) and by excluding other causes of respiratory distress. A diagnosis of neonatal pneumonia was made by presence of long-term radiological findings (increase in linear intensity unilaterally or bilaterally, diffuse granular appearance with air bronchograms, opacity areas) which suggested penumonia in newborns with respiratory distress. A diagnosis of pneumothorax was made by clinical evaluation and presence of pleural air in the affected side, separation of the lung from the chest wall and collaps of the lung on lung graphy.

A diagnosis of lung hemorrhage was made by bloody discharge or bleeding from the trachea, changes on lung graphy ranging from patchy perihilar parenchimal involvement to complete white appearance and worsening in the underlying lung disease. Apnea was defined as respiratory arrest which continued longer than 15 seconds accompanied by desaturation and bradycardia (9).

Total bilirubin was measured in the capillary blood sample obtained from the heel in all the patients hospitalized in NICU and phototherapy was administered when required. Capillary bilirubin measurement was done during regular follow-up examinations in infants given to the mother's side. Infants with a bilirubin level above the phototherapy limit were hospitalized in $\mathrm{NICU}$. Decisions for phototherapy and exchange transfusion were made in accordance with the American Pediatric Academy phototherapy and exchange transfusion curves in newborns with a gestational age above 35 weeks (10) and in accordance with the limits determined by birth weight in newborns with a gestational age below 35 weeks or a birth weight below $2500 \mathrm{~g}$ (11). In all the patients in the study, bilirubin levels were followed up by obtaining blood by heel prick three times a day until they were reduced below the phototherapy limit.

A diagnosis of neonatal sepsis was made by presence of risk factors including urogenital infection in the last three months, perpartum fever, history of premature rupture of membranes, preterm delivery and low birth weigth together with clinical (cardiopulmonary system findings including decrease in or loss of sucking and neonatal reflexes, apnea, bradicardia, groaning respiration, tachypnea, tachycardia, circulatory disorder, nutritional disorders, hypothermia-hyperthermia, lethargy, hypotonia) and laboratory (CRP $>1 \mathrm{mg} / \mathrm{dL}$, leukocytosis or leukopenia, an immature/mature leukocyte ratio of $>0,2$, thrombocytopenia) sepsis findings and blood culture. In pateints in whom sepsis was considered, $1 \mathrm{~mL}$ blood obtained under appropriate conditions was cultivated in "Bactec" medium for hemoculture. A diagnosis of urinary tract infection was made by finding growth of 103 colonies in one mililiter urine sample obtained by catheterization (12).

In all our patients, blood glucose and capillary hematocrit measurements were done at the postnatal second and sixth hours and 24 hours after delivery. A blood glucose level below $47 \mathrm{mg} / \mathrm{dL}$ was considered as hypoglycemia. Central venous hematocrit was measured in patients in whom capillary hematocrit was above $65 \%$ and the patients with a value above $65 \%$ were considered as polystemic. Serum calcium levels were measured on the postnatal 3rd and 10th days in all the infants included in the study. A total serum calcium level below $7,0 \mathrm{mg} / \mathrm{d}$ $\mathrm{L}$ and/or ionized calcium value below $2,5 \mathrm{mg} / \mathrm{dL}$ was considered as hypocalcemia (13). In all our patients, axillary temperature was measured postnatally. An axillary temperature above 36,50 $\mathrm{C}$ was considered as hypothermia. Nutritional difficulty was considered as delay in onset of breastfeeding and difficulty in continuing breastfeeding because of a disorder in concordance of sucking and swallowing.

Statistical analyses were performed using NCSS 2007 package program in the study. In evaluation of the data, descriptive statistical methods (mean, standard deviation), independent t-test for comparison of paired groups and chi- 
square and Fischer's exact test and odds ratio for comparison of quantitative data were used. Logistic regression analysis was used to determine the risk factors in late preterm newborns. The results were evaluated at a significance level of $p<0.05$ with a confidence interval of $95 \%$.

\section{Results}

2582 live infants were born in our hospital between May the 1 rst 2009 and May the 1st 2010. It was determined that 412 $(15,2 \%)$ of these were late preterm newborns. 220 late preterm newborns among these infants constituted the study group and 200 term newborns constituted the control group.

$111(51 \%)$ of the study group were male and 109 (49\%) were female and the male/female ratio was found to be $1,04.125$ infats (56.8\%) were born by cesarean section and 95 (43.2\%) infants were born by normal vaginal delivery. The mean birth weight in the late preterm newborns constituting our study group

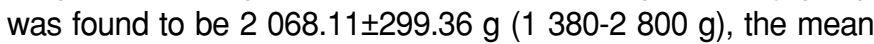
height was found to be $46.5 \pm 1.72 \mathrm{~cm}(42-51 \mathrm{~cm})$ and the mean head circumference was found to be $32 \pm 1.6 \mathrm{~cm}(28-37 \mathrm{~cm})$.

In comparison of late preterm newborns with term newborns, delivery by cesarean section and hospitalization in NICU was found with a significantly higher rate in preterm infants compared to term infants (Table 1). Again, the risk of hospitalization in
NICU was $7.37(4.56-11.91)$ fold higher in late preterm newborns.

When the infants were evaluated in terms of respiratory distress, respiratory problem was observed in four $(2 \%)$ of the term infants and in $70(31.8 \%)$ of the late preterm infants. The most commonly observed respiratory problem was transient tachypnea of the newborn (TTN) (20\%). The risk of respiratory distress syndrome (RDS) was found to be 32.64 fold higher and the risk of TTN was found to be 19.16 fold higher. While mechanical ventilation was not needed in any of the term infants $(0 \%)$, it was observed in $46(20.9 \%)$ of the late preterm infants (Table 2). The mean time of mechanical ventilation was found to be $2.89 \pm 2.23$ days. Presence of infection, hypothermia and jaundice requiring phototherapy were found with a statistically significantly higher rate in the late preterm group. Among late preterm infants diagnosed as sepsis $(n=18)$, Escherichia coli was isolated from hemoculture in 6 patients, klebsiella pneumonia was isolated in 5 patients, coagulase negative staphylococci were isolated in 4 patients and enterococcus spp. were isolated in 3 patients. In 7 late preterm infants diagnosed as urinary tract infection, escherichia coli $(n=3)$, klebsiella spp $(n=2), S$. epidermidis $(n=1)$ and enterococcus $\operatorname{spp}(n=1)$ were isolated from urinary culture. Phototherapy was performed in 15 $(7,59 \%)$ of term newborns and in $94(42.7 \%)$ of late preterm infants. Exchange transfusion was performed in $3(1.4 \%)$ of late

Table 1. Prenatal and perinatal findings of the infants in the study group

\begin{tabular}{|c|c|c|c|}
\hline & Term $(n=200)$ & Late preterm $(n=220)$ & p \\
\hline Maternal age (years) (mean \pm SD) & $27.9 \pm 5.0$ & $26.8 \pm 5.9$ & 0.048 \\
\hline Assisted reproductive technique (n) & 14 & 1 & 0.003 \\
\hline Multiple pregnancy (n) & 20 & 3 & 0.014 \\
\hline Maternal diabetes (n) & 8 & 4 & 0.476 \\
\hline Maternal smoking status (n) & 18 & 9 & 0.181 \\
\hline Preeclampsia (n) & 46 & 17 & 0.0006 \\
\hline Premature rupture of membranes $(\mathrm{n})$ & 12 & 14 & 0.650 \\
\hline Maternal urinary tract infection $(n)$ & 11 & 3 & 0.084 \\
\hline Mode of delivery (\%) & $\begin{array}{l}76.5 \\
23.5\end{array}$ & $\begin{array}{l}43.2 \\
56.8\end{array}$ & 0.0001 \\
\hline Apgar scores & $\begin{array}{l}8.36 \pm 0.66 \\
9.67 \pm 0.58\end{array}$ & $\begin{array}{l}7.33 \pm 1.52 \\
8.84 \pm 1.35\end{array}$ & $\begin{array}{l}0.0001 \\
0.0001\end{array}$ \\
\hline Male /Female (\%) & $49.5 / 50.5$ & $50.5 / 49.5$ & 0.845 \\
\hline Birth weight $(\mathrm{g})$ (mean \pm SD) & $3163.3 \pm 347.9$ & $2068.1 \pm 299.4$ & 0.0001 \\
\hline Birth height $(\mathrm{cm})($ mean \pm SD) & $49.1 \pm 0.7$ & $46.5 \pm 1.7$ & 0.0001 \\
\hline Head circumference $(\mathrm{cm})$ (mean \pm SD) & $34.6 \pm 0.4$ & $32.0 \pm 1.6$ & 0.000 \\
\hline Hospitalization in the Intensive Care Unit (\%) & 14 & 54.5 & 0.0001 \\
\hline Time in the Intensive care Unit (days) (mean \pm SD) & $4.1 \pm 1.3$ & $6.67 \pm 5$ & 0.001 \\
\hline
\end{tabular}


preterm infants (Table 3). Jaundice requiring treatment was found with a 9.72 fold higher rate in late preterm newborns. Causes of pathological jaundice included ABO incompatibility $(24.7 \%)$ and infection (24.7\%) with the highest rate in addition to preterm delivery. Other causes included feeding problem (9.3\%), polysthemia $(8.2 \%)$, Rh incompatibility $(7.2 \%)$ and cephal hematoma $(4.1 \%)$. In late preterm infants, feeding problems, hypoglycemia, convulsions, hypocalcemia and presence of apnea were found with a significantly higher rate compared to the control group. Among the infants hospitalized in the Neonatal Intensive Care Unit (NICU), one (0.5\%) of the term infants and $12(5.5 \%)$ of the preterm infants were lost $(\mathrm{p}=0.003)$. The risk of mortality was found to be 11,48 fold (1.48-89.16) higher in late preterm infants compared to the control group (Table 3 ).

\section{Discussion}

Late preterm infants constitute the most rapidly growing group among newborns, $8-9.1 \%$ of all births $(2,14,15)$ and $74 \%$ of preterm births (16). The main reason for the increase in preterm deliveries is the increase in late preterm deliveries $(17,18)$. An increase of $25 \%$ has been found in late preterm deliveries since 1990 (19). During our study period, the rate of late preterm deliveries was found to be $15,2 \%$. We think that this higher rate compared to the literature $(2,14,20)$ may be related with the fact that higher number of risky pregnancies are referred to the obstetrics clinic of our hospital, since our hospital is a reference center in our region.

Late preterm infants have been traditionally considered as term infants and they have been followed up and discharged in the same manner (5). However, these infants are not matured physiologically and metabolically yet compared to term infants. Recent studies have shown that the morbidity and health risks of late preterm infants are higher than expected and emphasized that these newborns should be approached more carefully $(4,21,22)$. Therefore, attention has been drawn to these late preterm infants who have been generally overlooked in the last few years and a gradually increasing interest has been started to be shown to the problems of this group.

Table 2. Comparison of the study groups in terms of postnatal morbidity and mortality

\begin{tabular}{|c|c|c|c|c|c|}
\hline & & $\begin{array}{l}\text { Term (200) } \\
\text { (n) (\%) }\end{array}$ & $\begin{array}{l}\text { Late preterm (220) } \\
\text { (n) (\%) }\end{array}$ & p & OR ( $95 \%$ confidence interval) \\
\hline Respiratory probl & $\begin{array}{l}\text { n } \\
\text { None } \\
\text { TTN } \\
\text { RDS } \\
\text { Neonatal } \\
\text { Neonatal pneumonia } \\
\text { PTX } \\
\text { Apnea }\end{array}$ & $\begin{array}{c}196(98) \\
3(1.5) \\
0(0) \\
0(0) \\
1(0.5) \\
0(0) \\
0(0)\end{array}$ & $\begin{array}{c}150(68.2) \\
44(20) \\
12(5.5) \\
6(2.7) \\
5(2.3) \\
3(1.4) \\
8(3.6)\end{array}$ & $\begin{array}{l}0.0001 \\
0.0001 \\
0.007 \\
0.091 \\
0.083 \\
0.006\end{array}$ & $\begin{array}{c}19.16(5.84-62.93) \\
32.64(1.92-65.09) \\
16.97(0.95-33.88) \\
6.53(0.75-56.54) \\
9.14(0.47-18.42) \\
16.04(0.91-79.91)\end{array}$ \\
\hline MV requirement & $\begin{array}{l}\text { None } \\
\text { Nasal CPAP } \\
\text { SIMV+PS }\end{array}$ & $\begin{array}{c}200(100) \\
0(0) \\
0(0)\end{array}$ & $\begin{array}{l}174(79.1) \\
25(11.4) \\
21(9.5)\end{array}$ & $\begin{array}{l}0.0001 \\
0.0001\end{array}$ & $\begin{array}{c}58.60(3.54-97.3) \\
49.41(2.97-82.19)\end{array}$ \\
\hline \multicolumn{2}{|c|}{$\begin{array}{l}\text { Jaundice requiring treatment } \\
\qquad \begin{array}{l}\text { Phototherapy } \\
\text { Exchange transfusion }\end{array}\end{array}$} & $\begin{array}{c}\text { Yok } \\
15(7.5) \\
0(0)\end{array}$ & $\begin{array}{c}185(92.5) \\
94(42.7) \\
3(1.4)\end{array}$ & $\begin{array}{c}123(55.9) \\
0.0001 \\
0.066\end{array}$ & $\begin{array}{c}9.42(5.22-17.02) \\
10.51(0.54-205.49)\end{array}$ \\
\hline \multicolumn{2}{|l|}{ Hypothermia } & $0(0)$ & $32(14.5)$ & 0.0001 & $69.14(4.20-113.9)$ \\
\hline \multicolumn{2}{|l|}{ Feeding problem } & $1(0.5)$ & $42(9.1)$ & 0.0001 & $46.95(6.39-144.86)$ \\
\hline \multicolumn{2}{|l|}{ Hypoglycemia } & $2(1)$ & $14(6.4)$ & 0.004 & $6.73(1.51-29.99)$ \\
\hline \multicolumn{2}{|l|}{ Convulsion } & $0(0)$ & $6(2.7)$ & 0.019 & $12.15(0.68-27.25)$ \\
\hline \multicolumn{2}{|l|}{ Polysthemia } & $3(1.5)$ & $9(4.1)$ & 0.111 & $2.80(0.75-10.50)$ \\
\hline \multicolumn{2}{|l|}{ Hypocalcemia } & $0(0)$ & 7 (3.2) & 0.011 & $14.09(0.80-48.42)$ \\
\hline
\end{tabular}

TTN: Transient tachypnea of the newborn,

RDS: respiratory distress syndrome,

MV: mechanical ventilation, PTX: Pneumothorax 
Diseases of late preterm infants lead to loss of lives even in countries with high per capita income giving developed health care service (16). Although the morbidity and mortality rates in these infants are lower compared to small preterm infants, they constitute a higher percent of the neonatal mortality rate because of their higher number. In various studies, a three fold increase in the mortality rate and a 8 fold increase in gestational age- specific mortality rate compared to term infants has been reported (23). Khashu et al. (16) found a 5,5 fold increase in neonatal mortality rates in late preterm infants compared to term infants. In two cohort studies performed in USA and Canada, Kramer et al. (24) reported that late preterm delivery was responsible of $6.3 \%$ and $9 \%$ of early neonatal mortality and $13.1 \%$ and $15.9 \%$ of neonatal mortality, respectively. In our study, the mortality rate $(5.5 \%)$ was found to be significantly higher (p:0.003, OR: 11,48) in late preterm infants compared to term infants similar to other studies $(2,16,20,24,25)$.

It has been reported that NICU requirement and internalization time in NICU are higher in late preterm infants compared to term infants (15). In the study performed by Raju TN et al. (6) in 2006, the rate of internalization in the intensive care unit was found to be $51 \%$ in late preterm infants and $16 \%$ in term infants, while the rate of internalization in NICU and the mean time of internalization (54.5\%/6.7 days) were significantly higher compared to term infants (14\%/4.1 days) ( $p=0.0001$, OR: 7.37 and p: 0.001, respectively) in our study.

Late preterm infants encounter with respiratory problems with a higher rate compared to term newborns. While the rate of patients who developed respiratory problem was 31.8\% in our study group, it was found to be $2 \%$ in the control group. Kalyoncu et al. (26) found respiratory distress with a rate of $44.8 \%$ in late preterm infants and with a rate of $6.7 \%$ in term infants and they reported that the most common cause of respiratory distress was TTN (49.6\%) and this was followed by RDS (20.5\%) and neonatal pneumonia (13.3\%). In the study performed by Shapiro-Mendoza CK et al. (2), it was concluded that TTN $(16.8 \%)$ and RDS (4.9\%) were observed with a higher rate in late preterm infants compared to term infants. In our stury, the rate of TTN was found to be $20 \%$ in late preterm infants and $1.5 \%$ in the control group. The rate of RDS was found to be $5.5 \%$ in late preterm infants, while it was not observed in term infants. Neonatal pneumonia which is one of the problems which can lead to respiratory distress in the newborn was observed with a rate of $2.7 \%$ in the study group, while it was not observed in the control group. Another condition which can lead to respiratory distress in the neonatal period is lung hemorrhage. Lung hemorrhage may develop primarily or secondary to mechanical ventilation support which is applied fot treatment in the neonatal period. Although there was no significant difference between the control group $(0.5 \%)$ and the study group $(2.3 \%)$ in terms of lung hemorrhage, it was found that the risk of development of lung hemorrhage was increased 6.53 fold in late preterm infants. There was no statistically significant difference between the control group (0\%) and the study group (1.4\%) in terms of presence of pneumothorax which leads to severe respiratory distress in the neonatal period. In the late preterm group, presence of pneumothorax was found with a 9.14 fold higher risk. These results were found to be compatible with the literature (2).

In preterm infants, MV support may be easily needed in the neonatal period as a result of development of respiratory distress. Mclntire DD et al. (15) found that late preterm infants needed respiratory support with a higher rate compared to term newborns. In our study, the need for MV support was found with a rate of $20.9 \%$ in the late preterm group, while no patient needed mechanical ventilation in the control group.

Nasocomial infections and sepsis have come to the forefront as causes of mortality in infants followed up in intensive care units. Newborn infants and especially preterm infants are predisposed to infection and thus sepsis because of their underdeveloped immune mechanisms. In our study, sepsis was observed with a rate of $8.2 \%$ in the late preterm group, while no patient developed sepsis among term newborns. Similarly, the rate of sepsis was found to be high in the literature (20).

Hypothermia has been reported to cause a severe problem in late preterm infants (20). The frequency of hypothermia was found to be $10 \%$ in late preterm infants and $0 \%$ in term infants by Wang ve ark. (14) and $6.3 \%$ in late preterm infants and $0 \%$ in term infants by Kalyoncu et al. (26). In our study, hypothermia was found with a rate of $14.5 \%$ in the late preterm group and was not observed in term infants.

In late preterm infants, jaundice can easily increase to levels which require treatment as a result of many factors including increased enterohepatic circulation related to feeding problems and inadequate excretion in the metabolism of bilirubin. In one study, the rate of jaundice was found to be $16.3 \%$ in late preterm infants and $3 \%$ in term infants and the most common causes of jaundice in late preterm infants were reported to be nutritional disorder and blood group incompatibilities (21). In our study, the rate of jaundice was $44.1 \%$ in late preterm infants and $7.5 \%$ in term infants. Excluding preterm delivery, the most common causes of pathological jaundice included $A B O$ incompatibility and infection. Other causes included feeding difficulty, polysthemia, $\mathrm{Rh}$ incompatibility and cephal hematoma.

Delayed breastfeeding and inadequate feeding may lead to fluid loss in the postnatal period after preterm delivery. In a study performed by Raju TN et al. (6), it was observed that late preterm infants most frequently encountered with feeding difficulty in the neonatal period. Late preterm infants are under risk in terms of neonatal hypoglycemia (27). Wang et al. (21) observed hypoglycemia with a 3.3 fold higher rate in late preterm infants compared to term newborns. In our study, the risk of feeding difficulty was 46.9 fold higher and the risk of hypoglycemia was 6.7 fold higher in late preterm infants. Presence of hypocalcemia is one of the early metabolic problems in preterm infants (28). In our study, hypocalcemia was 
found with a rate of $3.2 \%$ in late preterm infants and it was not observed in term infants $(p=0.011, O R=14.09)$.

Engle WA et al. (5) reported that apnea which is frequently considered as a problem of small preterm infants constituted a significant problem also in late preterm infants and found apnea with a rate of $4 \%$. Kalyoncu et al. (26) found apnea with a rate of $1.6 \%$ in late preterm infants and with a rate of $0 \%$ in term infants. We found apnea with a rate of $3.6 \%$ in late preterm infants and with a rate of $0 \%$ in term infants in our study.

Conclusively, neonatal morbidity and mortality rates are higher in late preterm infants compared to term infants. It is very important that these infants should be evaluated and closely monitored in terms of conditions including postnatal respiratory distress, jaundice, hypothermia, feeding problems, hypoglycemia and risk of infection. It is recommended that late preterm infants who have been discharged without requirement of internalization in NICU be called in the short-term for follow-up and closely monitored in terms of potential mortality and hospitalization.

\section{Conflict of interest: None declared.}

\section{References}

1. McLaurin KK, Hall CB, Jackson EA, Owens OV, Mahadevia PJ. Persistence of morbidity and cost differences between late-preterm and term infants during the first year of life. Pediatrics 2009; 123: 653-659.

2. Davidoff MJ, Dias T, Damus K, Russell R, Bettegowda VR, Dolan S, Schwarz RH, Green NS, Petrini J. Changes in the gestational age distrubition among US singleton births: impacts on rates of late preterm births, 1992 to 2002. Semin Perinatol 2006; 30: 8-15.

3. Shapiro-Mendoza CK, Tomashek KM, Kotelchuck M, Barfield W, Nannini A, Weiss J, Declercq E. Effect of late-preterm birth and maternal medical conditions on newborn morbidity risk. Pediatrics 2008; 121: e223-232.

4. Khashu M, Narayanan M, Bhargava S, Osiovich H. Perinatal outcomes associated with preterm birth at 33 to 36 weeks' gestation: a population-based cohort study. Pediatrics 2009; 123: 109-113.

5. Engle WA, Tomashek KM, Wallman C; Committee on Fetus and Newborn, American Academy of Pediatrics. "Late-preterm" infants: a population at risk. Pediatrics 2007; 120:1390-1401.

6. Raju TN, Higgins RD, Stark AR, Leveno KJ. Optimising care and outcome for late preterm infants: a summary of the workshop sponsored by the national institute of child health and human development. Pediatrics 2006; 118: 1207-1214.

7. Escobar GJ, Clark RH, Greene JD. Short-term outcomes of infants born at 35 and 36 weeks gestation: we need to ask more questions. Semin Perinatol 2006; 30: 28-33.

8. Rawlings JS, Smith FR. Transient tachypnea of the newborn: An analysis of neonatal and obstetric risk factors. Am J Dis Child 1984; 138: 869-871.
9. Abu-Shaweesh JM. Respiratory disorders in preterm and term infants. In: Martin RJ, Fanaroff AA, Walsh MC, (eds). Fanaroff \&Martin's neonatal-perinatal medicine. Diseases of the fetus and infant. St. Louis: Elsevier Mosby, 2011: 1141- 1206.

10. American Academy of Pediatrics Subcommittee on Hyperbilirubinemia. Management of hyperbilirubinemia in the newborn infant 35 or more weeks of gestation. Pediatrics 2004; 114: 297-316.

11. Maisels MJ. The clinical approach to the jaundiced newborn. In: Maisels MJ, Watchko JF, (eds). Neonatal jaundice. Amsterdam: Harwood Academic, 2000: 139-168.

12. Edwards MS. Postnatal bacterial infections. In: Martin RJ, Fanaroff AA, Walsh MC, (eds). Fanaroff \&Martin's neonatal-perinatal medicine. Diseases of the fetus and infant. St. Louis: Elsevier Mosby, 2011: 793-830.

13. Çoban A. Yenidoğanda metabolik sorunlar. İçinde: Neyzi $O$, Ertuğrul $T$, (yazarlar). Pediyatri. İstanbul: Nobel Matbaacllık, 2010: 453-466.

14. Consortium on Safe Labor, Hibbard JU, Wilkins I, Sun L, Gregory K, Haberman S, Hoffman M, Kominiarek MA, Reddy U, Bailit J, Branch DW, Burkman R, Gonzalez Quintero VH, Hatjis CG, Landy H, Ramirez $\mathrm{M}$, VanVeldhuisen P, Troendle J, Zhang J. Respiratory morbidity in late preterm births. JAMA 2010; 304: 419- 425.

15. McIntire D, Leveno KJ. Neonatal mortality and morbidity rates in late preterm births compared with births at term. Obstet Gynecol 2008; 111: 35-41.

16. Osrin D. The implications of late-preterm birth for global child survival. Int J Epidemiol 2010; 39: 645-649.

17. Laughon SK, Reddy UM, Sun L, Zhang J. Precursors for late preterm birth in singleton gestations. Obstet Gynecol 2010; 116: 1047-1055.

18. Ortigosa Rocha CO, Bittar RE, Zugaib M. Neonatal outcomes of latepreterm birth associated or not with intrauterine growth restriction. Obstet and Gynecol Int 2010: 231842.

19. Martin JA, Kung HJ, Mathews TJ, Hoyert DL, Strobino DM, Guyer B, Sutton SR. Annual summary of vital statistics: 2006. Pediatrics 2008; 121: 788-801.

20. Tomashek KM, Shapiro-Mendoza CK, Davidoff MJ, Petrini JR. Differences in mortality between late-preterm and term singleton infants in the United States, 1995- 2002. J Pediatr 2007; 151: 450-456.

21. Wang ML, Dorer DJ, Fleming MP, Catlin EA. Clinical outcomes of nearterm infants. Pediatrics 2004; 114: 372-376.

22. McLaurin KK, Hall CB, Jackson EA, Owens OV, Mahadevia PJ. Persistence of morbidity and cost differences between late preterm and term infants during the first year of life. Pediatrics 2009; 123: 653-659.

23. Loftin RW, Habli M, Snyder CC, Cormier CM, Lewis DF, Defranco EA. Late preterm birth. Rev Obstet Gynecol 2010; 3:10-19.

24. Kramer MS, Demisse K, Yang H, Platt RW, Sauvé R, Liston R. The contribution of mild and moderate preterm birth to infant mortality. JAMA 2000; 284: 843-849.

25. Pulver LS, Warnick GG, Stoddard GJ, Byington CL, Young PJ. Weigh for gestational age affects the mortality of late preterm infants. Pediatrics 2009; 123: e1072-1077.

26. Kalyoncu Ö, Aygün C, Çetinoğlu E, Küçüködük Ş. Neonatal morbidity and mortality of late-preterm babies. J Maternal-Fetal and Neonatal Med 2010; 23: 607-612.

27. Committee on Fetus and Newborn, Adamkin DH. Clinical reportpostnatal glucose homeostasis in late-preterm and term infants. Pediatrics 2011; 127: 575-579.

28. Picone S, Paolillo P. Neonatal outcomes in population of late-preterm infants. J Matern Fetal Neonatal Med 2010; 13: 116-120. 